\title{
T-cell trafficking plays an essential role in tumor immunity
}

\author{
Daniel J. Aires ${ }^{1,3} \cdot$ Masaru Yoshida ${ }^{2,4} \cdot$ Stephen K. Richardson ${ }^{1,5} \cdot$ Mei Bai $^{1,6} \cdot$ Luzheng Liu $^{1,7} \cdot$ Roberto Moreno $^{1,8}$. \\ Alexander J. F. Lazar $\mathbb{B}^{1,9}$. Jo A. Wick ${ }^{1,10} \cdot$ Benjamin E. Rich ${ }^{1,11} \cdot$ George Murphy $^{1} \cdot$ Richard S. Blumberg $^{2}$. \\ Robert C. Fuhlbrigge $^{1} \cdot$ Thomas S. Kupper ${ }^{1}$
}

Received: 31 August 2017 / Revised: 2 August 2018 / Accepted: 6 August 2018 / Published online: 23 October 2018

(c) United States \& Canadian Academy of Pathology 2018

\begin{abstract}
Distinct populations of effector memory T cells use different homing receptors to traffic to the skin and gut. Whether tissueselective $\mathrm{T}$ cells are needed for early rejection of a neoplasm growing in these tissues remains an open question. We chose to study an allogeneic tumor model because growth of such a fully mismatched tumor would signify a profound immune deficit. We implanted allogeneic tumor cells in the skin or gut of mice deficient in either $\alpha(1,3)$ fucosyltransferases IV and VII, enzymes critical for generating E-selectin ligands on skin-homing T cells, or $\beta 7$ integrin, a component of the $\alpha 4 \beta 7$ integrin ligand for the mucosal adressin MAdCAM. During the first 9 days after tumor implantation, FucTVII ${ }^{-1-}$ mice showed a profoundly impaired capacity to reject tumors growing in the skin, but readily rejected tumors implanted in the gut. Rejection of tumors in the skin was even more impaired in mice deficient in both FucTIV and FucTVII. This impairment was corrected by infusion of $\mathrm{T}$ cells from normal mice. By contrast, $\beta 7$ integrin $^{-1-}$ mice showed profoundly impaired rejection of tumors in the gut, but no defect in the skin tumor rejection. These differences were unrelated to antigen recognition or effector function of $\mathrm{T}$ cells, since all strains of mice were capable of generating tumor-specific CTLs in vitro against the tumor cell line used in vivo. These results demonstrate that T-cell homing defects in vivo impair immune surveillance of peripheral epithelial tissues in a specific and selective fashion.
\end{abstract}

\section{Introduction}

These authors contributed equally: Daniel J. Aires, Masaru Yoshida, Stephen K. Richardson

Electronic supplementary material The online version of this article (https://doi.org/10.1038/s41374-018-0124-6) contains supplementary material, which is available to authorized users.

Thomas S. Kupper

tkupper@bwh.harvard.edu

1 Harvard Skin Disease Research Center, Department of Dermatology, Brigham and Women's Hospital, Boston, MA, USA

2 Gastroenterology Division, Department of Medicine, Brigham and Women's Hospital, Boston, MA, USA

3 Present address: Division of Dermatology, Department of Internal Medicine, Kansas University Medical Center, Kansas City, KS, USA

4 Present address: Department of Gastroenterology, Kobe University, Kobe, Japan

5 Present address: Dermatology Associates of Tallahassee,
Cancers frequently arise in epithelial tissues that interface with the environment, including skin, lung, and gastrointestinal (GI) tract. The emergence of dramatic clinical results using immune checkpoint inhibitor antibodies for multiple cancers has rekindled interest in tumor immunity [1-4]; however, many unknowns still exist. For example, while many features of tumor immunity have been studied intensively, the role of tissue-selective effector

Tallahassee, FL, USA

6 Present address: McCarter \& English, Boston, MA, USA

7 Present address: Department of Dermatology, Northwestern University, Chicago, IL, USA

8 Present address: Department of Public Health, Galveston, TX, USA

9 Present address: Department of Pathology, M.D. Anderson Cancer Center, Houston, TX, USA

10 Present address: Department of Biostatistics, Kansas University Medical Center, Kansas City, KS, USA

11 Present address: Celcuity LLC, Minneapolis, MN, USA 
memory T-cell trafficking in the early rejection of tumors is incompletely understood [4-7]. To begin to address this question, we used mice with genetically engineered deficiencies in key T-cell skin- and gut-trafficking molecules and studied their impact on tumor immunity in these tissues. In order to set the highest possible threshold for immunosurveillance, we chose fully mismatched allogeneic tumors, mindful that such major antigenic differences would never occur in spontaneous tumors.

T-cell homing to skin, in both humans and mice, depends on the interaction of dermal microvascular selectins with specific carbohydrate ligands for E- and Pselectin expressed on specialized effector and memory $\mathrm{T}$ cells [8]. These carbohydrate epitopes, including the cutaneous lymphocyte-associated antigen expressed on skin-homing effector and memory $\mathrm{T}$ cells in humans, are formed by the action of key glycosyltransferases to generate terminally sialylated, fucosylated lactosamines related to sialyl-Lewis ${ }^{\mathrm{X}}[1,8]$. Both $\alpha(1,3)$-fucosyltransferase VII (FucTVII) and $\alpha(1,3)$-fucosyltransferase IV (FucTIV) have been reported to mediate glycosylation steps critical for the generation of E- and P-selectin ligands [9]. Mice deficient in FucTVII show diminished, although not absent, trafficking of $\mathrm{T}$ cells to skin; this defect is even more profound in mice lacking both FucTVII and FucTIV [9, 10].

T-cell homing to gut lamina propria does not appear to depend on selectins, but rather on the integrin $\alpha 4 \beta 7$, which initiates the multi-step extravasation process by binding to mucosal addressin cell adhesion molecule (MAdCAM) [6, 11]. Naive T cells express $\alpha 4 \beta 7$ at low levels, but $\alpha 4 \beta 7$ is much more highly expressed by effector and memory cells generated in gut-draining lymphoid tissue; these latter $\mathrm{T}$ cells selectively traffic to the laminia propria in the GI tract $[11,12]$. Mice deficient in $\alpha 4 \beta 7$ integrin have been shown to have altered immune cell populations in gut-associated lymphoid tissue, and altered responses to gastrointestinal viruses and parasites [13-16].

To study the influence of these tissue-selective T-cell homing molecules on early tumor immunity, we chose a tumor cell line (J558L) that could grow successfully and progressively in both skin and gut of syngeneic mice, and was rapidly rejected in both sites by $\mathrm{H}-2$ mismatched mice. We implanted tumor cells into skin or gut of allogeneic $\mathrm{C} 57 \mathrm{BL} / 6\left(\mathrm{H}-2^{\mathrm{d}}\right)$ mice deficient in organ-specific T-cell trafficking molecules to assess the role of such $\mathrm{T}$ cells in early tumor immunity. Because J558L cells are $\mathrm{H}-2^{\mathrm{b}}$ and thus completely mismatched at all $\mathrm{C} 57 \mathrm{Bl} / 6\left(\mathrm{H}-2^{\mathrm{d}}\right)$ major histocompatability loci, any observed tumor growth represents a significant defect in surveillance.

\section{Methods}

\section{Mice}

BALB/c and wild-type (WT) B6 mice were purchased from Charles River Laboratories Inc. (Wilmington, MA). FucT$\mathrm{VII}^{-1-}$ B6, FucTIV ${ }^{-1-} / \mathrm{VII}^{-1-} \mathrm{B} 6$, and $\beta 7^{-1-}$ B6 mice were kindly provided by John Lowe (Genentech, Inc.) and Norbert Wagner (University of Cologne), respectively. Strains were generated from C57BL/6, and inbred for well over 6 generations. Mice were housed under specific pathogen-free conditions at the animal facility of the Harvard Institutes of Medicine. Experiments were approved by the Harvard Medical Area Standing Committee on Animals.

\section{T-cell cytotoxicity assay}

WT B6, FucTVII ${ }^{-1-}$ B6, $\beta 7^{-1-}$ B6, or syngeneic BALB/c mice splenocytes were co-cultured for 5 days with mitomycin C-treated BALB/c splenocytes to produce effector cell populations. Cytotoxic T lymphocyte (CTL) activities were assayed with CytoxiLux flow cytometric cytotoxicity assay kits (OncoImmunin, Gaithersburg, MD) [17]. Briefly, TFL2 fluorescent dye-labeled target J558L cells were cultured in triplicate with effector cells in 96-well plates at various effector/target ratios for $3 \mathrm{~h}$ at $37^{\circ} \mathrm{C}$. Plates were centrifuged for $5 \mathrm{~min}$ at $1400 \mathrm{rpm}$. Cells were then incubated in fluorogenic caspase substrate $(75 \mu \mathrm{l} /$ well) for $30 \mathrm{~min}$ at $37^{\circ} \mathrm{C}$ followed by two phosphate-buffered saline (PBS) washes. Samples were obtained via FACSCalibur flow cytometer (Becton Dickinson, San Jose, CA). Data were analyzed using Flowjo software (Tree Star, Inc., San Carlos, CA). Target cell killing percent (\%target cells caspase staining $)=\left[\%\left(\right.\right.$ caspase $^{+} \mathrm{TFL}^{+}$cells $) /(\%$ total TFL $\left.\left.2^{+}\right)\right] \times 100 \%$.

\section{Tumor transplantation into skin and cecum}

Murine J558L BALB/c plasmacytoma was grown in RPMI with $10 \%$ fetal calf serum, $2 \%$ L-glutamate, and penicillin/ streptomycin. Injected cells were concentrated to $1 \times 10^{7}$ cells/mL RPMI (skin) or 3-4 × $10^{7}$ cells/mL PBS (gut). For tumors in the skin, mice were clipped $24-36 \mathrm{~h}$ pre-transplant, anesthetized with Avertin, and then $10^{6}$ live J558L cells were injected intradermally using a $30.5 \mathrm{G}$ needle. For tumors in the gut, the lower abdomen was sterilely incised, and the cecum was externalized. Next, $10^{6}$ live $\mathrm{J} 558 \mathrm{~L}$ cells were injected into the cecal lamina propria, and the cecum was replaced intraperitoneally. Incisions were closed with 4-0 silk or nylon sutures as described previously [18]. Tumor sizes were greatest diameter of grossly visible tumor mass at skin and gut injection sites. For histopathologic 
examination, skin and gut samples were fixed in $10 \%$ formalin, paraffin embedded, and sections submitted for hematoxylin-eosin staining.

\section{Tumor immunohistochemistry}

The $4 \mu \mathrm{m}$-thick formalin-fixed, paraffin-embedded tissue sections were examined. Slides were pre-treated with $10 \mathrm{mM}$ citrate, pH 6.0 (Zymed, South San Francisco, CA) for CD3 or $1.0 \mathrm{mM}$ EDTA pH 8.0 (Zymed) for CD138 in a pressure cooker (Decloaking Chamber, BioCare Medical, Walnut Creek, CA). Pre-diluted polyclonal rabbit anti-CD3 antibody (DAKO, Carpinteria, CA) or monoclonal antimurine CD138 antibody (Pharmingen, San Diego, CA) diluted 1:250 was applied for $1 \mathrm{~h}$ at room temperature. Rabbit anti-rat immunoglobulin antibody at 1:7500 dilution and DAKO Envision kits (DAKO) were used for detection.

\section{$\mathrm{CD3}^{+}$T-cell immunohistochemistry}

The $6 \mu \mathrm{m}$-thick frozen tissue sections were fixed in $-20{ }^{\circ} \mathrm{C}$ acetone for $5 \mathrm{~min}$, air dried, and then incubated with $5 \mu \mathrm{g} /$ $\mathrm{mL}$ rat anti-mouse $\mathrm{CD} 3$ monoclonal antibody (Antigenix America Huntington, NY) for $30 \mathrm{~min}$ at $25^{\circ} \mathrm{C}$. After extensive washing, sections were incubated with 1:200 biotinylated anti-rat IgG antibody (Vector, Burlingame, $\mathrm{CA}$ ) for $30 \mathrm{~min}$ at $25^{\circ} \mathrm{C}$, washed, and then incubated with avidin-biotin conjugate (ABC; Vector) for $30 \mathrm{~min}$ at $25^{\circ} \mathrm{C}$. Reaction product was detected by incubation with NovaRed (1 $\mathrm{min}$ ), and sections were counterstained with hematoxylin.

\section{Adoptive T-cell transfer}

Primed $\mathrm{T}$ cells were obtained from skin-draining lymph nodes of WT B6 mice that had been injected with J558L cells 9 days previously. T cells were purified by negative selection using mouse $\mathrm{CD}^{+}$T-cell enrichment columns (R\&D Systems, Minneapolis, MN). Next, $5 \times 10^{6} \mathrm{~T}$ cells were injected via tail vein into FucTVII ${ }^{-1-}$ B6 mice $48 \mathrm{~h}$ before J558L tumor cell transplantation. Similarly, J558Lnaive WT $\mathrm{B} 6 \mathrm{CD}^{+}{ }^{+}$and $\mathrm{CD} 8^{+} \mathrm{T}$ cells were purified from unmanipulated WT B6 splenocytes using mouse $\mathrm{CD}^{+}$and $\mathrm{CD}^{+}$T-cell enrichment columns (R\&D Systems, Minneapolis, $\mathrm{MN})$. Next, $5 \times 10^{6}$ naive $\mathrm{CD}^{+}$and $\mathrm{CD} 8^{+} \mathrm{T}$ cells were injected via tail vein into FucTVII ${ }^{-1-}$ B6 mice $48 \mathrm{~h}$ prior to dermal injection of J558L tumor cells.

\section{Statistical analysis}

Mean tumor size was compared between groups at prespecified times using nondirectional two-sample $t$-tests that account for unequal group variances. Two-sided $p$ values $<0.05$ were considered statistically significant.

\section{Results}

\section{FucTVII ${ }^{-I-}$ and $\alpha 4 \beta 7^{-I-}$ strains both generate J558L-reactive cytotoxic $T$ cells}

To assess whether C57/BL6 ( $\mathrm{H}-2^{\mathrm{b}}$ ) mice lacking $\alpha 4 \beta 7$ integrin $\left(\beta 7^{-1-}\right.$ B6) or FucTVII (FucTVII ${ }^{-l-}$ B6) could generate cytotoxic $\mathrm{T}$ cells to BALB/c targets in vitro, splenic $\mathrm{T}$ cells from each strain were activated in vitro via mixed lymphocyte reaction against BALB/c splenocytes, and were then assayed for capacity to kill J558L $\left(\mathrm{H}-2^{\mathrm{d}}\right)$ cells. There were no significant differences in the magnitude or efficiency of T-cell cytotoxicity among WT B6, $\beta 7^{-/-}$ B6, and FucTVII ${ }^{-1-}$ B6 (Figure S1). Neither transgenic strain showed defects in alloantigen responsiveness nor generation of tumor-specific cytotoxic effector cells.

\section{Allogeneic tumors implanted in the gut grew progressively in mice deficient in $\beta 7$ integrin but not deficient in FucTVII}

To examine anti-tumor immune responses in the gut, we injected J588L cells into cecal lamina propria of BALB/c, WT B6, FucTVII ${ }^{-1-}$ B6, and $\beta 7^{-1-}$ B6 mice. After 9 days, large tumors in the gut were observed both grossly and histologically in both syngeneic BALB/c (positive control) and $\mathrm{H}-2$ mismatched $\beta 7^{-I-} \mathrm{B} 6$ mice. By contrast, no tumor growth was detected grossly or histologically in $\mathrm{FucTVII}^{-/-}$ B6 or WT B6 mice (Figs. 1a and 2a). We assessed J588L immunohistochemistry using anti-CD138 (syndecan) antibodies. Large CD138-positive tumor cell aggregates were observed in cecal lamina propria in both the BALB/c and $\beta 7^{-1-}$ B6 mice (Fig. 2a). We next looked for T-cell infiltration using anti-CD3 antibodies. Day 19 BALB/c mice still showed virtually no T-cell infiltration (Fig. 3h). Tumors in $\beta 7^{-l-} \mathrm{B} 6$ mice showed some $\mathrm{CD}^{+}$infiltration by day 9 , and tumors were much smaller or undetectable by day 14 (data not shown.) Therefore, during the first 9 days, gut tumor rejection was delayed by $\beta 7$ integrin deficiency, but gut tumor immunity was preserved in FucTVII-deficient mice.

\section{Allogeneic tumors grew progressively in the skin of mice lacking FucTVII but not $\beta 7$ integrin}

To assess the capacity of mice to reject the same tumor in the skin, we injected J558L tumor cells intradermally into BALB/c, B6, $\beta 7^{-1-}$ B6, and FucTVII ${ }^{-1-}$ B6 mice, and measured tumors regularly (Fig. 4). As expected, tumors grew progressively in the skin of syngeneic BALB/c mice, and showed essentially no growth in allogeneic control B6 mice. In contrast, progressive tumor growth was seen in the skin of $\mathrm{FucTVII}^{-l-}$ B6 mice for the first 9-12 days. 

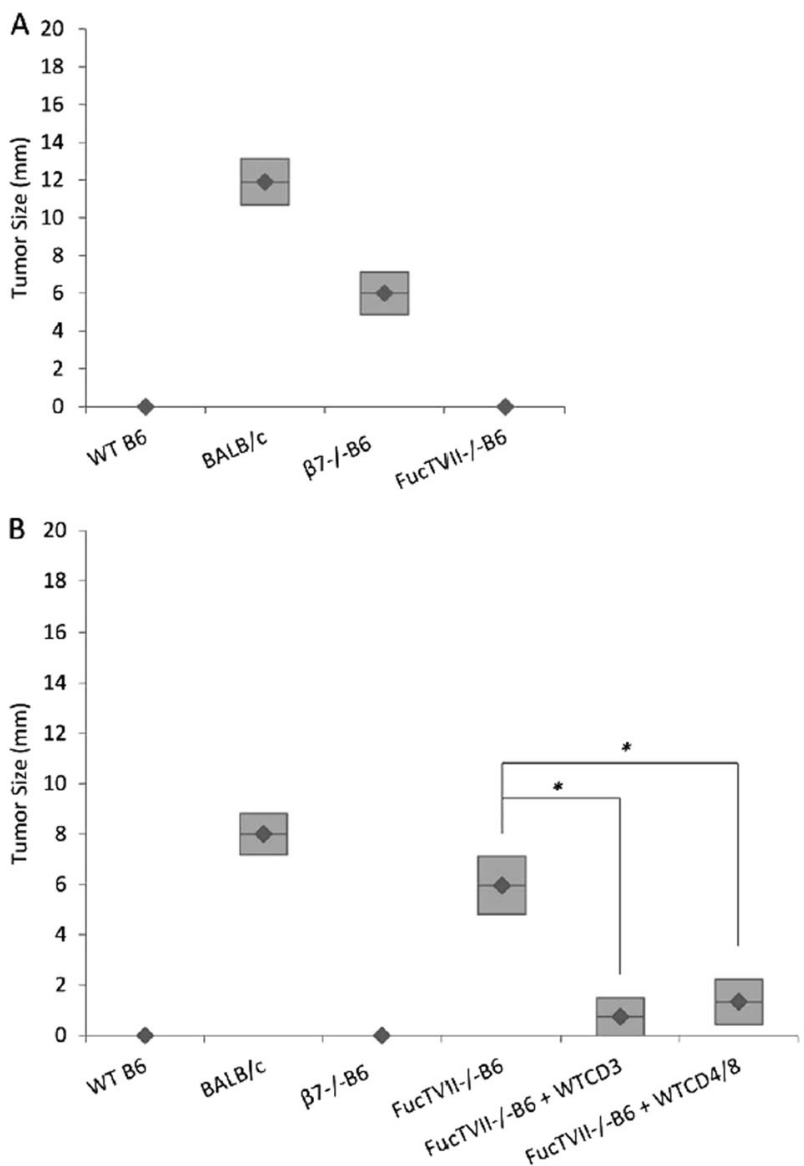

Fig. 1 a Early rejection of tumors in the gut was seen in FucTVII ${ }^{-1-}$ B6 mice but not in $\beta 7^{-/-}$B6 mice; $\mathbf{b}$ early rejection of tumors in the skin was seen in $\beta 7^{-1-}$ B6 mice but not in FucTVII ${ }^{-1-}$ B6 mice, and $\mathrm{CD}^{+} \mathrm{T}$ cells from wild-type mice largely restored tumor rejection in the skin of FucTVII ${ }^{-1-}$ B6 mice. a Tumors were measured 9 days after tumor cells were injected into gut. Large tumors were present in $\mathrm{BALB} / \mathrm{c}(n=9)$ and $\beta 7^{-/-}$B6 mice $(n=5)$, but not in WT B6 $(n=3)$ and FucTVII $^{-l-} \mathrm{B} 6(n=3)$ mice. b Tumors were measured 9 days after tumor cells were injected into skin. Tumors were present in BALB/c $(n=4)$ and FucTVII ${ }^{-1-}$ B6 $(n=8)$ mice, but not in WT B6 $(n=7)$ and $\beta 7^{-1-} \mathrm{B} 6$ mice $(n=5)$. Purified $\mathrm{CD}^{+}$cells from $\mathrm{J} 558 \mathrm{~L}$ tumor-primed WT B6 mice were injected into FucTVII ${ }^{-1-}$ B6 mice $(n$ =4) 2 days prior to tumor implantation. Purified $\mathrm{CD} 4^{+}$and $\mathrm{CD} 8^{+}$ T cells from tumor-naive WT B6 mice were injected into FucTVII ${ }^{-1-}$ B6 mice $(n=5) 2$ days prior to tumor implantation. The bars represent the mean \pm SE. Mean tumor size was significantly different for FucTVII $^{-1-}$ B6 and FucTVII ${ }^{-1-}$ B6+WTCD3 $(t(\mathrm{df}=9.99)=3.78, p$ $=0.003)$ and for FucTVII ${ }^{-1-}$ B6 and FucTVII ${ }^{-l}$ B6+WTCD4/8 $(t(\mathrm{df}$ $=10.99)=3.16, p=0.009)$. All tests are two-tailed t-tests. All tumor sizes in the skin and gut are based on histologic examination

A later time points, these tumors regressed. Figure $2 \mathrm{~b}$ shows gross and histological appearance of tumors at day 9. At this time point, $\mathrm{CD} 138^{+}$tumors in the skin of BALB/c mice and FucTVII $^{-1-}$ mice were readily identifiable and contained few $\mathrm{CD}^{+} \mathrm{T}$ cells. In contrast, on day 9 there was no gross or microscopic tumor in either WT B6 or in $\beta 7^{-l-}$ B6 mice, consistent with successful early tumor rejection. Thus, $\mathrm{FucTVII}^{-/-}$mice showed profoundly impaired early rejection of allogeneic tumor cells in the skin, but were able to rapidly reject the same tumor implanted in the gut mucosa. In contrast, $\beta 7^{-/-}$mice have impaired ability to reject allogeneic tumors implanted in the gut, but have fully intact skin tumor immunity; that is, they can rapidly reject the same tumor in the skin that they did not reject in the gut.

\section{Accelerated tumor growth in the skin of FucTVII ${ }^{-I-}$ B6 mice was prevented by adoptive transfer of WT B6 T cells}

To assess further whether the role of FucTVII in rejecting tumors in the skin depends on $\mathrm{CD}^{+} \mathrm{T}$ cells, we injected WT B6 T cells $\left(\right.$ FucTVII $^{+/+}$) into FucTVII ${ }^{-/-}$B6 mice before tumor implantation. Two separate experiments were performed using primed or naive WT B6 T cells, respectively. Primed $\mathrm{CD}^{+} \mathrm{T}$ cells were purified from skindraining lymph node of WT B6 mice that had been injected with J558L cells 9 days prior and injected into FucTVII $^{-/-}$ B6 mice 2 days before tumor implantation. FucTVII $^{-1-}$ B6 mice that received primed $\mathrm{WT} \mathrm{B} 6 \mathrm{CD}^{+}{ }^{+} \mathrm{T}$ cells showed little or no tumor growth in the skin at day 9 , in contrast to the large tumors in the skin of unmanipulated $\mathrm{FucTVII}^{-/-}$ B6 mice (Fig. 1b). To determine if this protective response depended on pre-exposure to antigen in the skin, naive $\mathrm{CD}^{+}$and $\mathrm{CD}^{+}$splenocytes were purified from unmanipulated WT B6 mice and injected into FucTVII ${ }^{-1-}$ B6 mice 2 days before tumor implantation. As with primed T cells, FucTVII $^{-1-}$ B6 mice that received naive WT B6 T cells showed little or no tumor growth in the skin at day 9 . Together, these data suggest that tumor rejection of J588L cells in the skin by B6 mice is dependent upon T cells that can express FucTVII, and upon the capacity of T cells to enter skin where they can recognize alloantigen and mediate anti-tumor effector functions.

\section{Tumors grew more rapidly in the skin of mice lacking both FucTIV and FucTVII}

Since skin leukocyte homing is diminished but not absent in mice lacking FucTVII, we performed additional experiments in mice that lack both FucTVII and FucTIV and therefore do not express any selectin ligands. We injected J558L cells intradermally into BALB/c, FucTVII ${ }^{-1-}$ B6, and FucTIV $^{-1-} / \mathrm{VII}^{-1-}$ B6 mice. As before, tumors grew progressively in the skin of syngeneic $\mathrm{BALB} / \mathrm{c}$ mice (Fig. 4), and in the skin of FucTVII ${ }^{-1-}$ mice until days 9-12, after which tumors began to regress. In contrast, tumor growth in the skin of $\mathrm{FucTIV}^{-1-} / \mathrm{FucTVII}^{-1-}$ B6 mice was very robust over the first 15 days, outstripping even that in syngeneic BALB/c mice (Fig. 4). Tumors in FucTIV $^{-/-} /$FucTVII $^{-1-}$ B6 mice subsequently shrank, however, and were ultimately rejected. 
Fig. 2 a Tumors grew in the gut of $\beta 7^{-1-}$ B6 mice but not FucTVII $^{-1-}$ B6 mice; b tumors grew in the skin of FucTVII $^{-1-}$ B6 mice but not $\beta 7^{-1-}$ B6 mice. a Histology of J558L tumor implantation sites at 9 days after implantation showed large aggregates of CD138/Syndecan + J558L tumor cells in cecal lamina propria in both $\mathrm{BALB} / \mathrm{c}$ and $\beta 7^{-1-}$ B6 recipients, but not in WT B6 or FucTVII ${ }^{-1-}$ B6 mice. Representative histopathology preparations are shown for each (magnifications in parentheses). b Tumors grew in the skin of FucTVII $^{-1-}$ B6 mice but not $\beta 7^{-1-} \mathrm{B} 6$ mice. Histology of J558L tumor implantation sites at 9 days after implantation showed large dermal aggregates of CD138/ Syndecan $^{+}$J558L tumor cells in both BALB/c and FucTVII ${ }^{-/-}$ B6 recipients, but not in WT B6 or $\alpha 4 \beta 7^{-1-}$ B6 mice.

Representative histopathology preparations are shown for each (magnifications in parentheses)
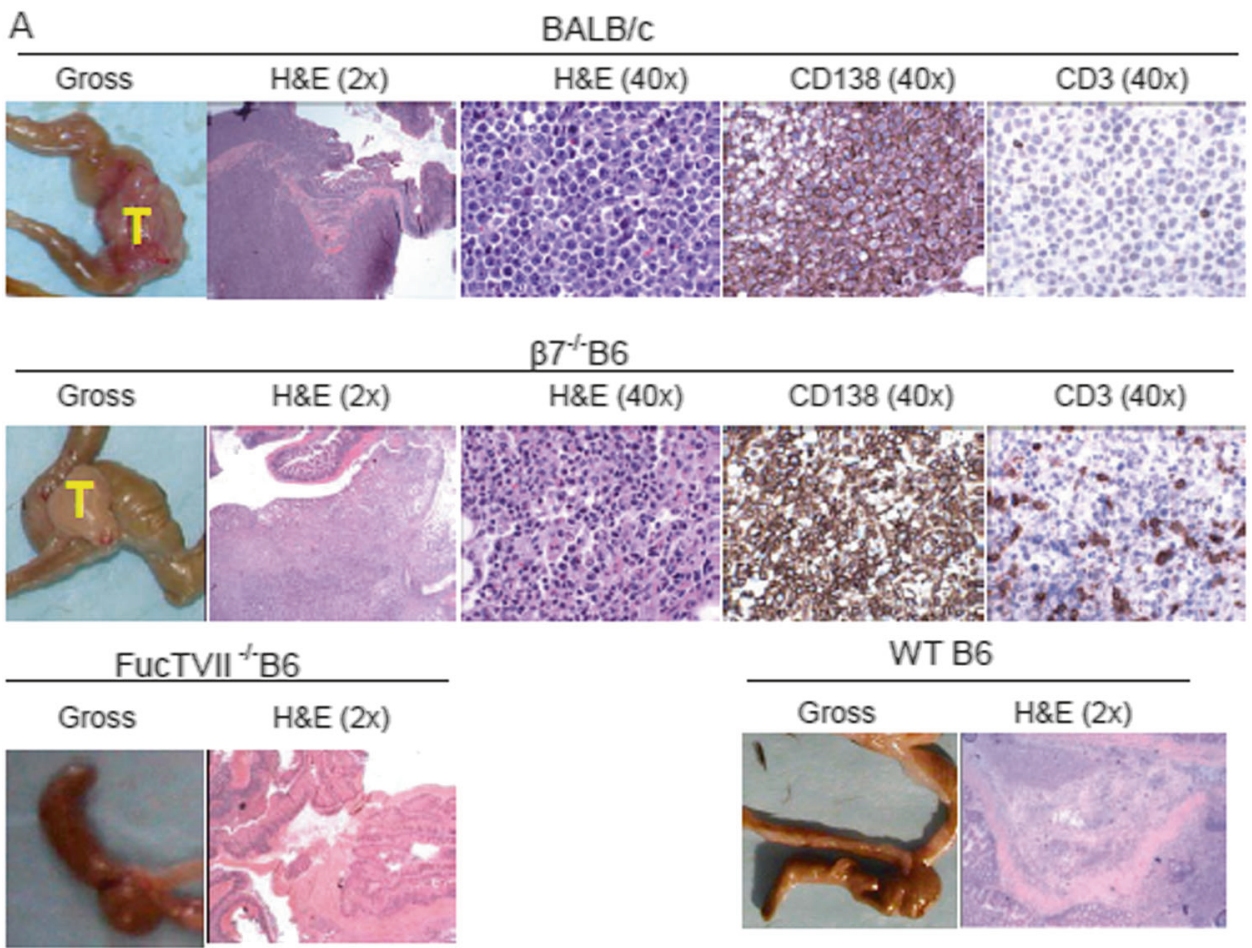

B

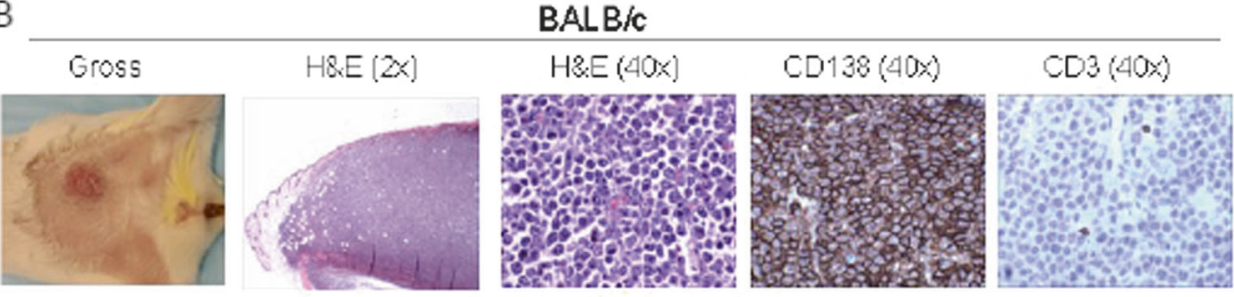

FucTVI|-·B6
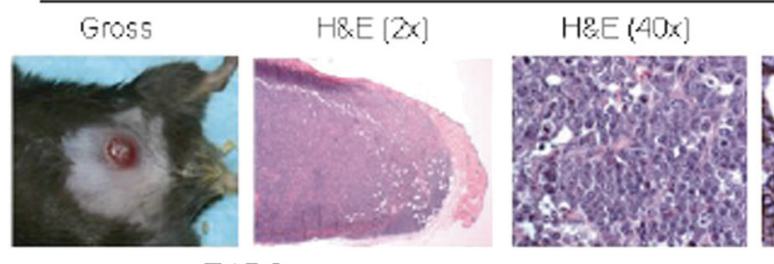

CD138 (40x)

CD3 (40x)

$\beta 7^{+B 6}$

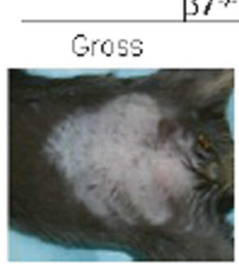

$H \& E(2 x)$

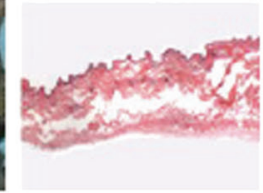

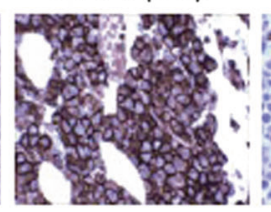

WT B6

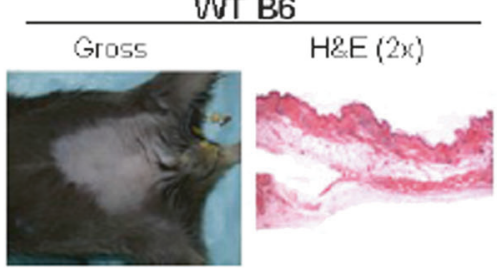

Delayed CD3 effector T-cell infiltration of tumors in FucTVII $^{-l-}$ and FucTIV ${ }^{-1-} /$ FucTVII $^{-1-}$ skin

Despite early tumor growth in the skin, both FucTVII ${ }^{-1-}$ and FucTIV $^{-/-} /$FucTVII $^{-1-}$ B6 mice ultimately rejected J558L tumors. We assessed whether this was associated with $\mathrm{CD}^{+}{ }^{+} \mathrm{T}$-cell infiltration by performing immunohistochemistry of tumors from these mice at various time points (Fig. 3). As expected, reduced or delayed T-cell infiltration correlated with tumor rejection delays across the different mouse strains (Fig. 3). WT B6 showed mild-to-moderate T-cell infiltrates at day 3 (Fig. 3a), and robust T-cell infiltrates by day 7 (Fig. 3b). Mice with deletion of FucTVII or FucTIV and FucTVII showed delays in both T-cell infiltration and tumor regression. Tumors in the skin of FucTVII $^{-l-}$ B6 mice showed 


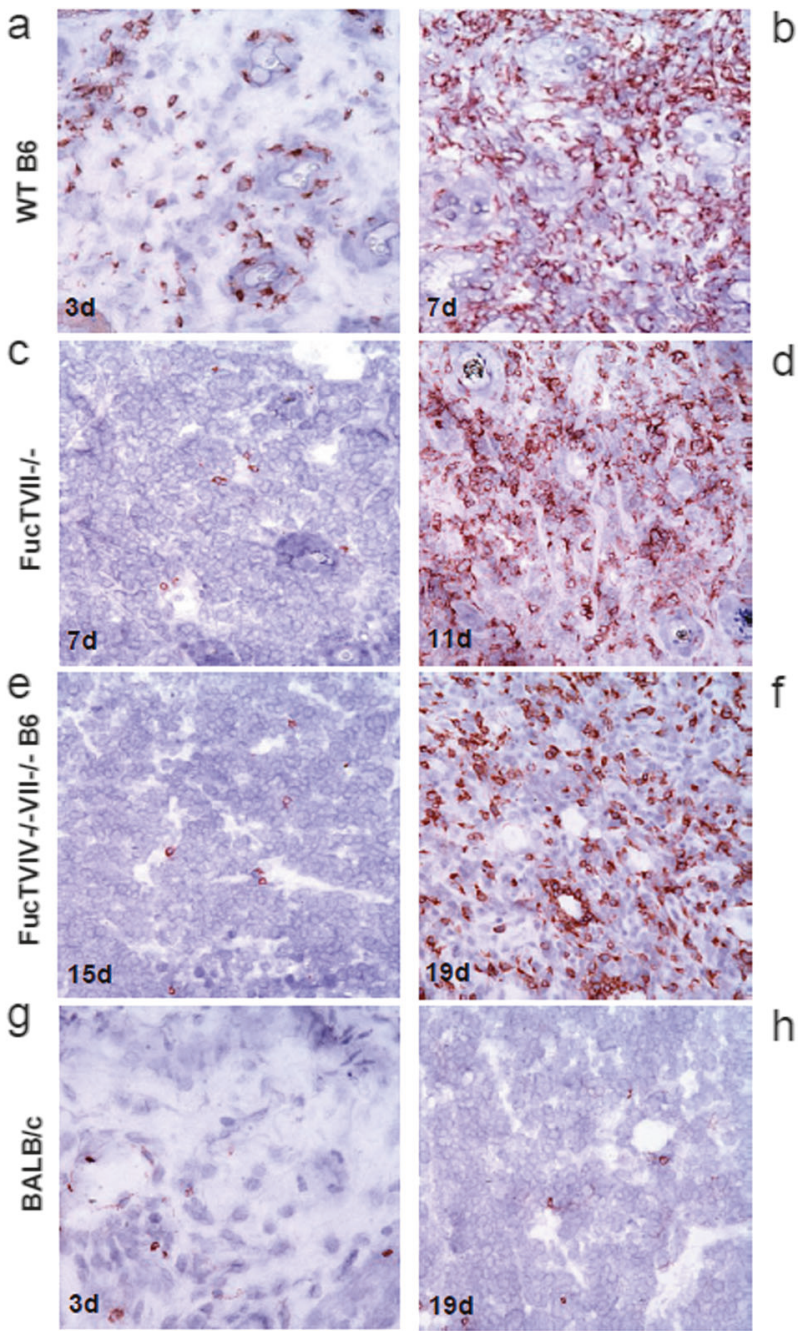

Fig. 3 Infiltration of tumors in the skin by $\mathrm{CD}^{+}$cells correlates with delay in allogeneic tumor rejection seen in FucTVII ${ }^{-1-}$ and FucTIV ${ }^{-1-} / \mathrm{VII}^{-1-}$ mice. a Tumors from WT B6 mice showed mild-tomoderate $\mathrm{CD}^{+}$infiltrate as early as 3 days after tumor implantation. b Tumors from WT B6 mice showed robust infiltrate at 7 days. c Tumors from FucTVII $^{-1-}$ B6 mice showed minimal infiltrate at 7 days. d Tumors from FucTVII ${ }^{-1-}$ B6 mice showed significant $\mathrm{CD}^{+}$infiltrate at 11 days, as tumors started to regress. e Tumors from doubleknockout FucTIV ${ }^{-1-} / \mathrm{VII}^{-1-}$ B6 mice showed minimal infiltrate at 15 days. f Tumors from double-knockout FucTIV ${ }^{-1-} / \mathrm{VII}^{-1-} \mathrm{B} 6$ mice showed significant $\mathrm{CD}^{+}$infiltrate at 19 days, as tumors started to shrink. $\mathbf{g}$ BALB/c showed minimal $\mathrm{CD} 3^{+}$infiltrate at 3 days. h BALB/ c still showed minimal infiltrate at 19 days. Representative histopathology preparations are shown for each

little infiltrate at 7 days (Fig. 3c), but significant infiltrate at 11 days as tumors started to regress (Fig. 3d). FucTIV ${ }^{-1-} / \mathrm{VII}^{-1-}$ B6 mice showed minimal infiltrate even at 15 days (Fig. 3e); however, they showed significant $\mathrm{CD}^{+}$ infiltrates at 19 days as tumors started to regress (Fig. 3f). By comparison, $\mathrm{BALB} / \mathrm{c}$ mice showed only trace infiltration of both early (day 3, Fig. 3g) and late (day 19, Fig. 3h) samples.

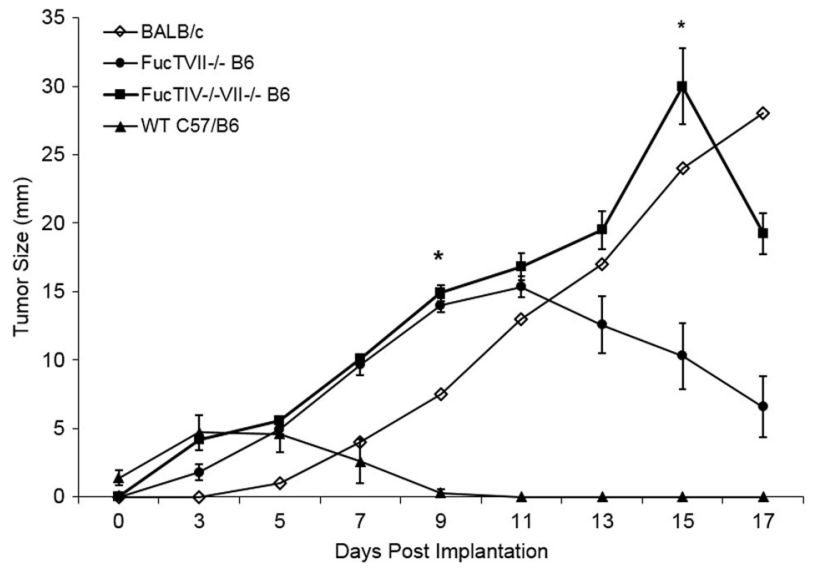

Fig. 4 J558L tumors showed early growth in the skin of BALB/c and FucTVII $^{-1-}$ B6 mice but not WT B6 mice; early tumor growth was even greater in the skin of double-knockout FucTIV $^{-1-} / \mathrm{VII}^{-1-} \mathrm{B} 6$ mice than in single-knockout FucTVII ${ }^{-1-}$ B6 mice. J558L cells were injected into abdominal skin and external dimensions of the resulting tumors were measured. Tumors grew progressively in the skin of syngeneic BALB/c mice $(n=1)$ and allogeneic FucTVII ${ }^{-1-}$ B6 mice $(n=7)$ for the first 9-11 days. Tumors grew faster in double-knockout FucTIV $^{-l-} / \mathrm{VII}^{-1-}$ B6 mice $(n=11)$ than either BALB/c or singleknockout FucTVII ${ }^{-1-}$ B6 mice $(n=5)$ (day 15, $t=5.31, p<0.001$ ). Tumors began to regress later in the double-knockout FucTIV ${ }^{-1-} /$ VII ${ }^{-I-}$ B6 mice versus the single-knockout FucTIV ${ }^{-I-} / \mathrm{VII}^{-1-}$ B6 mice. In a separate experiment, J558L tumor cells injected into abdominal skin of allogeneic WT B6 mice $(n=5)$ did not show significant growth. Of note, no tumor growth was seen in >15 WT B6 mice. Comparisons of mean tumor size at day 9 show tumor size was significantly larger in single-knockout FucTVII ${ }^{-1-}$ B6 mice $(n=5)(t=22.4, p<0.001)$ and double-knockout FucTIV ${ }^{-1-} / \mathrm{VII}^{-1-}$ B6 mice $(n=11)(t=21.8, p<$ $0.001)$ than in WT B6 $(n=5)$. Comparisons of mean tumor size at day 15 show tumors were significantly larger in double-knockout FucTIV ${ }^{-I-} / \mathrm{VII}^{-I-}$ B6 mice $(n=11)$ than single-knockout FucTVII ${ }^{-I}$ B6 mice $(n=5)(t=22.4, p<0.001)$. All tests are two-tailed $t$-tests. The bars represent the mean \pm SE. These tumor measurements were taken in vivo and include surrounding skin and associated inflammatory infiltrates, and so tumor sizes may be overstated

\section{Discussion}

Epithelial interfaces with the environment, including skin, gut, and lung, are frequent sites of injury, infection, and malignant tumor development. Distinct populations of memory effector $\mathrm{T}$ cells have been identified that traffic preferentially to skin and gut, respectively [8]. This trafficking is mediated or facilitated by expression of $\alpha 4 \beta 7$ on gut-homing memory effector $\mathrm{T}$ cells, and by $\mathrm{E}$ - and $\mathrm{P}$ selectin ligands on skin-homing memory effector $\mathrm{T}$ cells [8]. In this study, we asked whether mice deficient in these skin- or gut-homing molecules would show a tissue-specific deficit in rejection of an immunogenic allogeneic tumor. If early tumor immunosurveillance is independent of tissuespecific T-cell homing, mice deficient in homing molecules should have unimpaired early tumor immunity. On the other hand, if tumor immunosurveillance is related to tissuespecific T-cell trafficking, then even highly immunogenic 
allogeneic tumors might be functionally ignored in a tissueselective fashion when key trafficking molecules are absent. To investigate this hypothesis, H-2 ${ }^{\mathrm{d}}$ tumors (J588L) were implanted in the skin and gut, respectively, of C57BL/6 (H$2^{\mathrm{d}}$ mismatched) (a) WT, (b) FucTVII ${ }^{-/-}$, and (c) $\beta 7^{-1-}$ mice as well as control (d) BALB/c (H-2 ${ }^{\mathrm{d}}$ syngeneic) mice, and tumor growth was monitored over time. Although mindful that spontaneous tumors are never mismatched, we chose fully major histocompatibility complex-mismatched tumors to highlight the role of trafficking. In other words, survival of a fully mismatched tumor implies a very profound immunosurveillance defect.

The data demonstrate that unrestrained initial $\mathrm{H}-2^{\mathrm{d}}$ tumor growth occurred in the skin of FucTVII ${ }^{-1-}$ B6 mice and the gut of $\alpha 4 \beta 7^{-1-}$ B6 mice (Figs. 1 and 2). However, FucTVII $^{-1-}$ mice readily rejected the same tumor in the gut, and $\alpha 4 \beta 7^{-1-}$ mice readily rejected this tumor implanted in the skin. These data, coupled with in vitro results confirming that both mouse strains produce functional cytotoxic $\mathrm{T}$ lymphocytes capable of recognizing $\mathrm{J} 558 \mathrm{~L}$ tumor antigens, suggest that the observed tumor immunity defect was the result of impaired tissue-specific homing of effector $\mathrm{T}$ cells, rather than impaired antigen recognition or response.

To test the hypothesis that FucTVII ${ }^{-/-}$mice have no other impediment to effective anti-tumor immunity than defective recruitment of $\mathrm{T}$ cells into skin, we adoptively transferred purified WT (FucTVII+/+) B6 T cells into FucTVII $^{-/-}$B6 mice $48 \mathrm{~h}$ before tumor implantation. Transferring either naive or primed WT $\mathrm{T}$ cells prevented J588L tumor growth in the skin of FucTVII $^{-/}$mice (Fig. 1). Thus, effector T cells expressing FucTVII, but not those deficient in FucTVII, were capable of recognizing and rejecting allogeneic tumors in the skin of FucTVII-deficient hosts. These results also demonstrated that FucTVII $^{+}$ $\mathrm{T}$ cells were sufficient for tumor rejection without requiring other FucTVII ${ }^{+}$bone marrow-derived leukocytes, such as dendritic cells, macrophages, or neutrophils.

In a similar fashion we also show that the $\beta 7$ integrin chain, which forms heterodimers with both $\alpha 4$ and $\alpha \mathrm{E}$ integrin chains, is required for early rejection of allogeneic tumors in the gut. Absence of $\beta 7$ integrin allowed significant early growth of implanted H-2-mismatched tumors in the gut, despite their profound immunogenicity. These experiments did not allow us to address the question of whether this effect was due to the absence of $\alpha E \beta 7$ versus $\alpha 4 \beta 7$, or both. However, absence of $\beta 7$ integrin did not inhibit alloantigen recognition and response in vitro, or early rejection of $\mathrm{H}-2$ identical tumors from skin, indicating that in a non-gut microenvironment $\beta 7^{-1-} \mathrm{T}$ cells traffic normally and exhibit potent anti-tumor activity.

It is of interest to note that mice deficient in FucTVII, which reduces but does not eliminate expression of T-cell selectin ligands, showed delayed tumor suppression, but were ultimately able to recognize and suppress intradermal implanted tumor. To further elucidate the impact of T-cell surveillance defects on allogeneic tumor growth, we examined tumor growth in the skin of C57BL/6 mice lacking both fucosyltransferases IV and VII. These mice do not make any E- or P-selectin ligands and have a much more profound skin-homing defect. We found that tumors grew more rapidly in FucTIV and VII doubleknockout mice than in FucTVII single knockouts, and that infiltrates were delayed longer in the double knockouts (Figs. 3 and 4). These in vivo data show that increasing the T-cell homing defect correlates with increased tumor surveillance defect. Furthermore, although immunohistochemical stains showed profound inhibition of $\mathrm{CD}^{+} \mathrm{T}$-cell infiltration during early tumor growth in FucT-deficient mice, development of significant T-cell infiltrates at later time points was associated with tumor regression. It remains unclear by what mechanism $\mathrm{T}$ cells are ultimately able to enter skin-based tumors in FucTIV- and VIIdeficient mice, though we speculate that even the very few cells that enter by non-specialized means will eventually proliferate and mediate tumor suppression. It is important to recall that $\mathrm{H}$-2-mismatched tumors are intrinsically more immunogenic than any other tumor, and that when anatomical barriers are disrupted by tumor growth, rejection is inevitable.

Immunosurveillance at epithelial interfaces with the environment can be thought of as occurring on several different levels [8]. Our results are consistent with a model of secondary immunosurveillance in which peripheral epithelial tissues such as skin and gut are patrolled by subsets of memory $\mathrm{T}$ cells expressing tissue-selective trafficking molecules that allow them to circulate or emigrate to tissues under normal, homeostatic conditions, or are resident to skin (i.e., in the absence of obvious inflammation) [19-21]. These observations have important implications for studies that seek to induce immune responses in patients with widespread cancer. If our model is correct, then tumor vaccination delivered appropriately through skin or skindraining lymph nodes may help generate effector $\mathrm{T}$ cells that more efficiently enter skin [22]. Results from related studies in our laboratory support this prediction [23].

\section{Limitations}

One limitation of this study can also be viewed as a strength. Our hypothesis was that tissue-specific trafficking molecules on skin- and gut-homing effector/memory $\mathrm{T}$ cells, respectively, were essential for the entry of tumorspecific $\mathrm{T}$ cells into skin and gut and subsequent tumor rejection. We used a highly artificial tumor system $(\mathrm{H}-2$ complete mismatch) to test our hypothesis in the most stringent possible way, as such tumors are highly 
immunogenic. We were surprised by how large such tumors could grow in lamina propria and dermis in the absence of $\mathrm{T}$ cells that could specifically infiltrate skin or gut. Only when anatomical barriers were disrupted by large growing tumors could systemic $\mathrm{T}$ cells gain access to them, whereupon they were rapidly rejected.

Another limitation is that we used adoptive transfer pooled WT CD4 and CD8 cells to recover tumor immunity; this prevented analysis of relative contributions of each Tcell subset.

Acknowledgements We are grateful to Carol Botteron for comments, and John D Omobono and Christina Stephenson for help with preparation of the figures.

Funding This work was supported by the NIH grants T32 AR07098, R01 AI040124, R01 AR065807, and R37 AI25082 (all to TSK), and was also supported in part by Frontiers: The Heartland Institute for Clinical and Translational Research CTSA KL2RR033177 (awarded to the University of Kansas Medical Center, to JAW). The contents are solely the responsibility of the authors and do not necessarily represent the official views of the NIH.

\section{Compliance with ethical standards}

Conflict of interest The authors declare that they have no conflict of interest.

\section{References}

1. Sackstein R, Schatton T, Barthel SR. T-lymphocyte homing: an underappreciated yet critical hurdle for successful cancer immunotherapy. Lab Invest. 2017;97:669.

2. Sharma P, Allison JP. The future of immune checkpoint therapy. Science. 2015;348:56-61.

3. Adusumilli PS, Cha E, Cornfeld, Davis T, Diab A, Dubensky TW, et al. New Cancer Immunology Agents in Development: a report from an associated program of the $31^{\text {st }}$ Annual Meeting of the Society for Immunotherapy of Cancer, 2016. J Immunother Cancer. 2017;5:50.

4. Mahoney KM, Rennert PD, Freeman GJ. Combination cancer immunotherapy and new immunomodulatory targets. Nat Rev Drug Discov. 2015;14:561.

5. Dunn GP, Old LJ, Schreiber RD. The immunobiology of cancer immunosurveillance and immunoediting. Immunity. 2004; 21:137-48.

6. Grivennikov SI, Greten FR, Karin M. Immunity. inflammation, and cancer. Cell. 2010;140:883-99.

7. Zitvogel L, Tesniere A, Kroemer G. Cancer despite immunosurveillance: immunoselection and immunosubversion. Nat Rev Immunol. 2006;6:715-27.

8. Kupper TS, Fuhlbrigge RC. Immune surveillance in the skin: mechanisms and clinical consequences. Nat Rev Immunol. 2004;4:211-22.

9. Smithson G, Rogers CE, Smith PL, Scheidegger EP, Petryniak B, Myers JT, et al. Fuc-TVII is required for $\mathrm{T}$ helper 1 and $\mathrm{T}$ cytotoxic 1 lymphocyte selectin ligand expression and recruitment in inflammation, and together with Fuc-TIV regulates naive $\mathrm{T}$ cell trafficking to lymph nodes. J Exp Med. 2001;194: 601-14.

10. Erdmann I, Scheidegger EP, Koch FK, Heinzerling L, Odermatt B, Burg G, et al. Fucosyltransferase VII-deficient mice with defective E-, P-, and L-selectin ligands show impaired $\mathrm{CD} 4+$ and $\mathrm{CD} 8+\mathrm{T}$ cell migration into the skin, but normal extravasation into visceral organs. J Immunol. 2002;168: $2139-46$.

11. Johansson-Lindbom B, Agace WW. Generation of gut-homing $\mathrm{T}$ cells and their localization to the small intestinal mucosa. Immunol Rev. 2007;215:226-42.

12. Gorfu G, Rivera-Nieves J, Ley K. Role of beta7 integrins in intestinal lymphocyte homing and retention. Curr Mol Med. 2009;9:836-50.

13. Kato S, Hokari R, Matsuzaki K, Iwai A, Kawaguchi A, Nagao S, et al. Amelioration of murine experimental colitis by inhibition of mucosal addressin cell adhesion molecule-1. J Pharmacol Exp Ther. 2000;295:183-9.

14. Masopust D, Jiang J, Shen H, Lefrancois L. Direct analysis of the dynamics of the intestinal mucosa CD8 $\mathrm{T}$ cell response to systemic virus infection. J Immunol. 2001;166:2348-56.

15. Kuklin NA, Rott L, Feng N, Conner ME, Wagner N, Müller W, et al. Protective intestinal anti-rotavirus B cell immunity is dependent on alpha 4 beta 7 integrin expression but does not require IgA antibody production. J Immunol. 2001;166: 1894-902.

16. Artis D, Humphreys NE, Potten CS, Wagner N, Müller W, McDermott JR, et al. Beta7 integrin-deficient mice: delayed leukocyte recruitment and attenuated protective immunity in the small intestine during enteric helminth infection. Eur J Immunol. 2000;30:1656-64.

17. Liu L, Chahroudi A, Silvestri G, Wernett ME, Kaiser WJ, Safrit JT, et al. Visualization and quantification of T cell-mediated cytotoxicity using cell-permeable fluorogenic caspase substrates. Nat Med. 2002;8:185-9.

18. Yamori M, Yoshida M, Watanabe T, Shirai Y, Iizuka T, Kita T, et al. Antigenic activation of Th1 cells in the gastric mucosa enhances dysregulated apoptosis and turnover of the epithelial cells. Biochem Biophys Res Commun. 2004;316: 1015-21.

19. Park CO, Kupper TS. The emerging role of resident memory $\mathrm{T}$ cells in protective immunity and inflammatory disease. Nat Med. 2015;21:668.

20. Watanabe R, Gehad A, Yang C, Scott LL, Teague JE, Schlapbach C, et al. Human skin is protected by four funcationally and phenotypically discrete populations of resident and recirculating memory T cells. Sci Transl Med. 2015;7:279ra39.

21. Park, CO, Fu, X, Jiang, X, Pan, Y, Teague, JE, Collins, N, et al. Staged development of long-lived T-cell receptor $\alpha \beta$ TH17 resident memory T-cell population to Candida albicans after skin infection. J Allgergy Clin Immunol. 2018;142:647-662. Epub 2017 Nov 9.

22. Liu L, Zhong Q, Tian T, Dubin K, Athale SK, Kupper TS. Epidermal injury and infection during poxvirus immunization is crucial for the generation of highly protective $\mathrm{T}$ cell-mediated immunity. Nat Med. 2010;16:224.

23. Jiang $X$, Clark RA, Liu L, Wagers AJ, Fuhlbrigge RF, Kupper TS. Skin infection generates non-migratory memory CD8 $+\mathrm{T}(\mathrm{RM})$ cells providing global skin immunity. Nature. 2012;483:227-31. 